\title{
Dehumidification Effect of Polymeric Superabsorbent SAP-LiCl Composite Desiccant-Coated Heat Exchanger with Different Cyclic Switching Time
}

\author{
Bivas Panigrahi ${ }^{1}{ }^{\mathbb{D}}$, Yu Sheng Chen ${ }^{1}$, Win Jet Luo ${ }^{1,2, * \mathbb{C}}$ and Hung Wei Wang ${ }^{1}$ \\ 1 Department of Refrigeration, Air Conditioning and Energy Engineering, \\ National Chin-Yi University of Technology, Taichung 41170, Taiwan; bivas@ncut.edu.tw (B.P.); \\ a910136841116@gmail.com (Y.S.C.); aa851027aa@gmail.com (H.W.W.) \\ 2 Graduate Institute of Precision Manufacturing, National Chin-Yi University of Technology, \\ Taichung 41170, Taiwan \\ * Correspondence: wjluo@ncut.edu.tw; Tel.: +886-42392-4505 (ext. 2960)
}

Received: 10 October 2020; Accepted: 16 November 2020; Published: 19 November 2020

\begin{abstract}
This study investigated a composite polymer desiccant material's performance, which is prepared by impregnating solid desiccant such as sodium polyacrylate (SAP) on to hygroscopic salts such as lithium chloride $(\mathrm{LiCl})$. Dehumidification performance of the proposed composite polymer desiccant (SAP-LiCl) was analyzed by coating the suitable weight percentage $(\mathrm{wt} \%)$ of the desiccant onto a single fin-tube heat exchanger (FTHE) system and testing the desiccant-coated heat exchanger (DCHE) in a testing tunnel under various operating conditions. Net dehumidification efficacy of DCHE in terms of sorption and desorption amount and thermal performance $\left(\mathrm{COP}_{\text {th }}\right)$ were analyzed. For instance, with processed air inflow temperature, relative humidity and regeneration temperature setting of $30{ }^{\circ} \mathrm{C}, 80 \% \mathrm{RH}$ and $70{ }^{\circ} \mathrm{C}$, DCHE's sorption, desorption amount and $\mathrm{COP}_{\text {th }}$ were recorded as high as $945.1 \mathrm{~g}, 1115.1 \mathrm{~g}$, and 0.39 , respectively. It was further realized that the performance of the DCHE could be enhanced by modulating the cyclic switching time for dehumidification and regeneration processes. For instance, with the aforementioned processed airflow conditions, when the cyclic switching time tuned as $60 \mathrm{~min}$ instead of $10 \mathrm{~min}$ for a total time period of $120 \mathrm{~min}$, there is a net $58 \%$ improvement to the $\mathrm{COP}_{\text {th }}$ of the system. It was further observed that, under the same time period corresponding to the increase in cyclic switching time, the overall $\mathrm{COP}_{\text {th }}$ can be enhanced; however, the water vapor sorption and desorption amounts of desiccant were decreased.
\end{abstract}

Keywords: composite polymer desiccant; fin-tube heat exchanger; vapor sorption; vapor desorption; cyclic switching time; $\mathrm{COP}_{\text {th }}$

\section{Introduction}

The last few decades have witnessed rapid urbanization as well as industrialization. It is further predicted that the globe's primary energy requirement will see at least a $40 \%$ surge in the next two decades [1]. It has been further highlighted that $40 \%$ of total energy consumption around the world accounted for the buildings from which 50\% comes from the air conditioning system [1-3]. It can be noted that $40 \%$ of the total air-conditioning load is latent load, which is related to the moisture content handlings of the air-conditioning space [3]. To reduce net latent load, desiccant dehumidifiers have been developed, which is used to remove the moisture from the air either through the absorption or adsorption mechanism. The last few decades have witnessed significant research development towards the design and application of various desiccant dehumidifiers, which can be broadly classified into three major categories, namely, rotary desiccant wheel, fixed bed, and desiccant-coated heat 
exchangers (DCHEs). Each technology has their advantages and disadvantages over each other, and extensive details in this regards can be found in several literature studies [1,4-7]. Among all the three aforementioned technologies, DCHEs are considered as the most efficient methodology to reduce the overall cooling load with improved dehumidification with the least energy budget expenditure, hence employed for many real-life applications [5]. Along with air-conditioning technology, DCHEs are being used in absorption chillers, heat pumps [3,8], and even for water harvesting [9].

Desiccant-coated heat exchangers are basically fin-tube heat exchangers (FTHEs), which are comprised of desiccant-coated aluminum (Al) fins, where copper $(\mathrm{Cu})$ tubes are embodied within it [10]. Al fins are coated with either solid or polymer desiccants on it, and when the process air passes through it, the vapors are captured through the desiccants. To achieve isotherm sorption, the cold water is supplied through the copper tubes while ambient air passes through the DCHEs. Meanwhile, hot water is supplied through the copper tubes for the regeneration of captured vapor. It was realized that the efficiency of DCHE largely depends on the desiccant material property and the temperature of working medium supply. Conventional solid desiccant material such as silica gel is widely used desiccant material in DCHE towards moisture removal [3]. To further improve the sorption capability, silica gel was further dispersed within lithium chloride $(\mathrm{LiCl})$, calcium chloride $\left(\mathrm{CaCl}_{2}\right)$, and potassium formate $\left(\mathrm{CHKO}_{2}\right)$ solution to realize a net improvement in the sorption capability $[11,12]$. Other desiccant materials such as zeolite, Metal-Organic Frameworks (MOF) and composite carbon desiccant have also shown their efficacy in improving the net isotherm sorption amount of the DCHE [13,14].

To further improve the vapor sorption, material scientists have devised cross-linked polymers with a base of acrylates and acrylamides [15], which are coined as superabsorbent polymers (SAP). SAP possesses superlative capacity towards water absorption as it can retain water up to 2-3 times its original weight $[1,16]$. At a similar working condition, dehumidification capacity of SAP was found to be superior to other available solid desiccants such as silica gel $[15,17]$. SAP was further impinged within hygroscopic salts such as $\mathrm{LiCl}$ solution to prepare composite super desiccant polymer [16]. The composite super desiccant polymer's sorption capacity was tested on desiccant wheels, and it was realized that sorption capacity is $2 \sim 3$ times better than traditional solid desiccant material silica gel [18]. Recent studies have extensively highlighted that the composite desiccant-coated FTHEs demonstrate superlative capacity towards the dehumidification process $[7,10]$. For instance, in a recent study, Vivek et al. evaluated the PVA (polyvinyl alcohol)-LiCl-coated heat exchanger's performance that illustrates a 20-60\% improvement in the dehumidification capacity [10]. Although the efficacy of the composite polymer SAP-LiCl has shown its efficacy towards improved vapor sorption $[16,18]$, its performance on a FTHE is still unknown. Hence, the objective of this work is to evaluate the dehumidification performance of a SAP-LiCl-coated heat exchanger in various environmental conditions. The appropriate concentration of SAP in the $\mathrm{LiCl}$ solution was first determined for efficient vapor sorption and desorption through a static experiment in a controlled programmable constant temperature and humidity chamber. Subsequently, the fin-tube heat exchangers were coated with the optimized amount of the proposed desiccant, and a dynamic experiment within an air tunnel was carried out to evaluate the performance of the proposed composite desiccant in various process airflow conditions and cycling switching times between the dehumidification and regeneration process

\section{Materials and Experimental Methods}

\subsection{Desiccant Coating Preparation and Static Performance Measurement}

To prepare the composite desiccant solution, appropriate amounts of lithium chloride $(\mathrm{LiCl})$ were mixed with water maintained at a temperature of $50^{\circ} \mathrm{C}$. Subsequently, approximate amounts of superabsorbent polymers (SAP) were added into the aqueous $\mathrm{LiCl}$ solution and constantly stirred until a desired homogeneous solution was obtained. Three resultant desiccant solutions with three different concentrations of SAP $(16.6 \mathrm{wt} \%, 33.3 \mathrm{wt} \%$, and $50.0 \mathrm{wt} \%)$ were tested to find out the efficacy of the composite desiccant polymer material and its optimal concentration towards moisture 
sorption and desorption. The resultant solution uniformly adhered to an aluminum sheet of $4 \times 4 \mathrm{~cm}$ (width $\times$ breadth) dimension. Subsequently, the desiccant coated on the aluminum sheet underwent a baking process in an oven at a temperature of $80^{\circ} \mathrm{C}$ for $5 \mathrm{~h}$ towards the hardening and drying of the desiccant materials. The vapor sorption and desorption capacity of the desiccant-coated Al sheets were quantified for five different temperature settings in a controlled programmable constant temperature and humidity chamber. The timeframes of both the tests were set to a total period of 15,000 s, and the moisture sorption and desorption were recorded at every $1000 \mathrm{~s}$, by measuring the weight of the aluminum sheet.

\subsection{Dynamic Performance Measurement}

\subsubsection{Immersion Coating on FTHE}

To remove any unnecessary pollutants from the surface of the heat exchanger fins, it was first immersed in a mixture of citric acid and water solution and underwent an ultrasonic bath at a temperature of $50^{\circ} \mathrm{C}$ for a time period of $90 \mathrm{~min}$. Subsequently, the heat exchanger was further cleaned with water and air-dried. The optimized concentration of desiccant material was further uniformly coated on the heat exchanger through immersion coating technology, and the whole setup underwent baking in an industrial oven maintained at a temperature of $80^{\circ} \mathrm{C}$ for a period of $60 \mathrm{~h}$.

\subsubsection{Experimental Setup}

The schematic illustration of the experimental setup is illustrated below in Figure 1. The experimental setup was comprised of an acrylic chamber, an air environment-controlled chamber, two water baths, ultrasonic humidifiers, fans, and a desiccant-coated fin-tube heat exchanger. During the experiment, the air was supplied from the environment-controlled chamber at a flow rate of $1.8 \mathrm{~m}^{3} / \mathrm{min}$ with constant temperature and humidity condition. Aluminum honeycomb panels were fitted on the front and backend of the DCHE chamber to supply a uniform airflow. Six temperature and humidity sensors were fitted before and after DCHE to record the incoming and processed airflow. For the regeneration process, the water was supplied to the DCHE chamber through a water pump, and the temperature was constantly monitored through a temperature sensor.

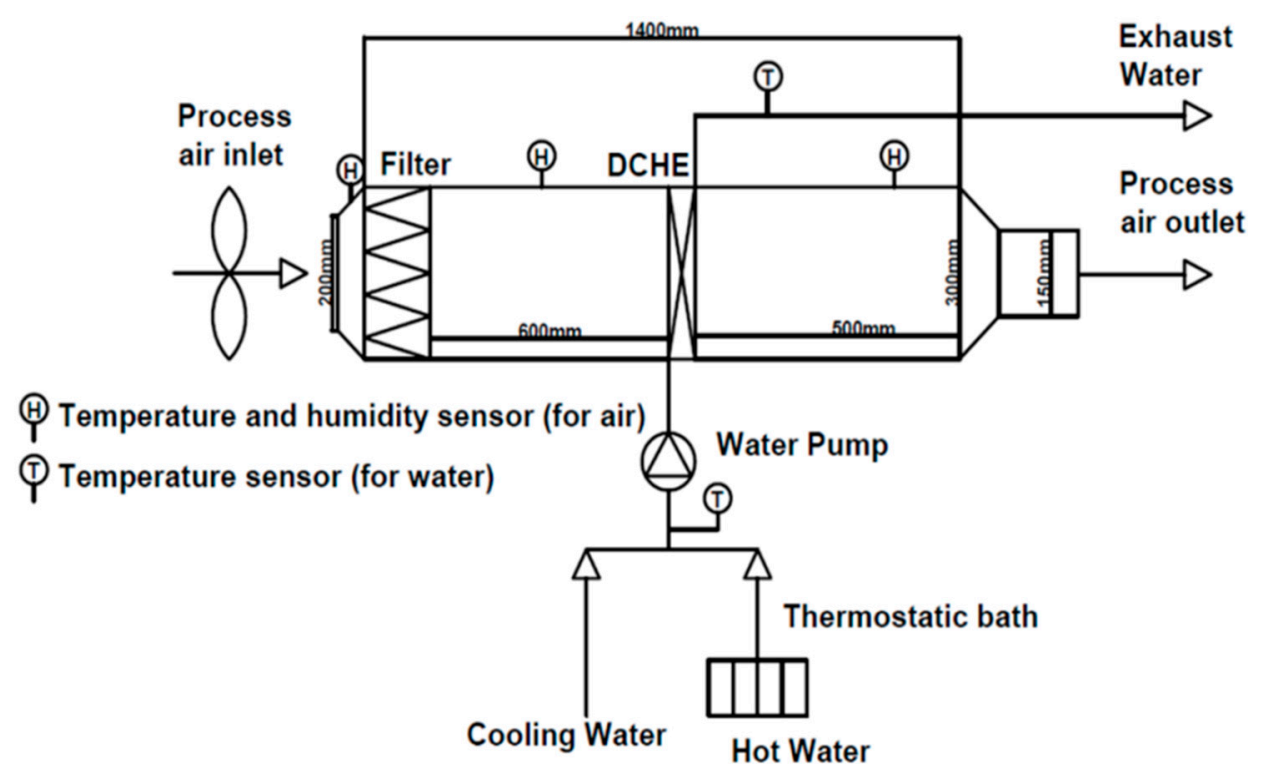

Figure 1. Schematic illustration of the experimental setup. 


\subsubsection{Theoretical Performance Analysis}

The moisture removal rate $\left(M_{\text {vap }}\right)$ of the DCHE can be quantified by measuring the inlet and outlet humidity ratios and the mass flow rate of the process air as provided in the underneath Equation (1).

$$
M_{\text {vap }}=\dot{m}_{a}\left(W_{a, \text { out }}-W_{a, \text { in }}\right),
$$

where $\dot{m}_{a}$ is the mass flow rate of air and $W_{a, \text { in }}$ and $W_{a, \text { out }}$ are the inlet and outlet humidity ratios of the process air, respectively.

The vapor sorption or desorption amounts $\left(G_{\text {vap }}\right)$ were determined through Equation (2) by taking integral of the moisture removal rate with respect to time $(\tau)$.

$$
G_{\text {vap }}=\int_{0}^{\tau}\left|M_{\text {vap }}\right| d t
$$

where $\tau$ is the time period for the vapor sorption or desorption process.

The vapor sorption or desorption amount $\left(G_{a}\right)$ of desiccant material per unit area $\left(\mathrm{g} / \mathrm{cm}^{2}\right)$ can be further quantified by dividing the vapor sorption or desorption amounts $\left(G_{\text {vap }}\right)$ by the area of fin $\left(A_{f i n}\right)$,

$$
G_{a}=\frac{G_{\text {vap }}}{A_{\text {fin }}}
$$

The vapor sorption or desorption ability per unit mass of the desiccant $\left(G_{m}\right)$ was further determined by dividing vapor sorption or desorption amounts $\left(G_{v a p}\right)$ by the mass of the desiccant $\left(M_{\text {des }}\right)$ coated on DCHE,

$$
G_{m}=\frac{G_{v a p}}{M_{\text {des }}} .
$$

To find out the overall energy efficiency of DCHE, the average thermal performance $C O P_{\text {th }}$ was quantified, which is defined as the ratio of the cooling capacity of air $\left(Q_{c o o l}\right)$ to the heat exchange of water during an effective dehumidification $\left(Q_{d e h}\right)$ and regeneration process $\left(Q_{\text {reg }}\right)$.

$$
\mathrm{COP}_{\text {th }}=\frac{Q_{\text {cool }}}{Q_{\text {deh }}+Q_{\text {reg }}}=\frac{\int_{0}^{\tau_{\mathrm{d}}} \dot{m}_{a} \times \Delta H \mathrm{dt}}{\int_{0}^{\tau_{\mathrm{d}}+\tau_{\mathrm{r}}}\left\{\left(m_{w} \times C_{P} \times \Delta T_{\text {deh }}\right)+\left(\dot{m}_{w} \times C_{P} \times \Delta T_{\text {reg }}\right)\right\} \mathrm{dt}}
$$

where $\dot{m}_{a}$ and $\dot{m}_{\text {water }}$ are the mass flow rate of the process air and the regeneration hot water, respectively, in $\mathrm{kg} / \mathrm{s}, \Delta H$ represents the difference in enthalpies of the process before and after DCHE, respectively, in $\mathrm{kJ} / \mathrm{kg}$, and $C_{p}$ is the specific heat of the regeneration hot water at a constant pressure in $\mathrm{kJ} / \mathrm{kg} \mathrm{K}$. $\Delta T$ is the temperature difference of water supply to $\left(T_{w, \text { in }}\right)$ and exhausting $\left(T_{w, \text { out }}\right)$ from the DCHE, respectively. $\tau_{d}$ and $\tau_{r}$ are the time periods for the vapor sorption and desorption process.

\subsubsection{Uncertainty Analysis}

The system uncertainties may emanate from instruments, physical environment, and human inadequacies. The system uncertainties for this work were quantified using the previously established protocols $[19,20]$. The instrument errors that influence the uncertainty analysis majorly emanate from the programmable constant temperature and humidity system (Model-150-00-SP-SD, Giant Force Instrument Enterprise Co., Ltd., Taiwan, $0-100{ }^{\circ} \mathrm{C} \pm 0.3{ }^{\circ} \mathrm{C}, 10-98 \% \mathrm{RH} \pm 3 \% \mathrm{RH}$ ), temperature-controlled water bath (Model-D-620, Great Tide Instrument Co., Ltd., Taiwan, $-20-100{ }^{\circ} \mathrm{C} \pm 0.1^{\circ} \mathrm{C}$ ), precision electronic scale (Model-AB323, Dehe Weighing Apparatus Co., Ltd., Taiwan, 0-320 g $\pm 0.003 \mathrm{~g}$ ), electric heating plate (Model-HP303D, Ten Billion Technology Co., Ltd., Taiwan, $0-350{ }^{\circ} \mathrm{C} \pm 1{ }^{\circ} \mathrm{C}$ ), anemometer (Model-TES-3142, TES Co., Ltd., Taiwan, $1-80 \mathrm{~m} / \mathrm{s} \pm 3 \%$ ), temperature probe (Model-HF532, Hsing Nan Import \& Export Co., Ltd., Taiwan, $-40-85{ }^{\circ} \mathrm{C} \pm$ 
$0.1^{\circ} \mathrm{C}$ ), humidity probe (Model-HC2-IC302, Hsing Nan Import \& Export Co., Ltd., Taiwan, 0-100\% $\mathrm{RH} \pm 0.8 \% \mathrm{RH}$ ) and liquid flow meter (Model-NW20-NTN, JETEC Electronics Co., Ltd., Taiwan, $1.5-20 \mathrm{~L} / \mathrm{min} \pm 2 \%)$. The uncertainty in moisture removal rate $\left(M_{v a p}\right)$, vapor sorption or desorption amounts $\left(G_{\text {vap }}\right)$, vapor sorption or desorption ability per unit area $\left(G_{a}\right)$, vapor sorption or desorption ability per unit mass $\left(G_{m}\right), \mathrm{COP}_{\text {th }}$ and energy consumption (E) were quantified within the range of $\pm 2.2 \%, \pm 2.2 \%, \pm 4.2 \%, \pm 6.5 \%, \pm 3.7 \%$, and $\pm 4.75 \%$, respectively. An extensive detail regarding the uncertainty analysis can be found in one of our recently published articles [20].

\section{Results and Discussions}

\subsection{Performance Analysis of Desiccant in a Static Test Environment}

To test the weight concentration of sodium polyacrylate (SAP) in the composite desiccant solution's (SAP-LiCl) sorption amount, experiments were conducted with a single aluminum sheet coated with $16.6 \mathrm{wt} \%, 33.3 \mathrm{wt} \%$, and $50.0 \mathrm{wt} \%$ of SAP in the desiccant solution, and the experiment was conducted in a programmable constant temperature and humidity chamber by maintaining the humidity ratio at $80 \% \mathrm{RH}$. The sorption kinetics was recorded at a different temperature of $20^{\circ} \mathrm{C}, 25^{\circ} \mathrm{C}, 30^{\circ} \mathrm{C}, 35^{\circ} \mathrm{C}$, and $40{ }^{\circ} \mathrm{C}$ for a time period of $15,000 \mathrm{~s}$ (left column of underneath Figure 2). It was observed that, irrespective of SAP concentration (i.e., $16.6 \mathrm{wt} \%, 33.3 \mathrm{wt} \%$, and $50.0 \mathrm{wt} \%$ ), the sorption amount of the desiccants increases corresponding to the increase in temperature. For instance, after 15,000 s, the sorption amount for a $16.6 \mathrm{wt} \%$ desiccant-coated $\mathrm{Al}$ sheet was measured as $2.005 \mathrm{~g} / \mathrm{g}$ when the chamber temperature was maintained at $20^{\circ} \mathrm{C}$. With a similar desiccant concentration, the sorption amount increases to $3.916 \mathrm{~g} / \mathrm{g}$, when the chamber temperature was maintained at $40{ }^{\circ} \mathrm{C}$, suggesting a $48 \%$ net increment in the sorption amount. A similar trend in the vapor sorption was recorded for the other two weight concentrations (i.e., $33.3 \mathrm{wt} \%$ and $50.0 \mathrm{wt} \%$ ). Upon comparison, it was found that, under similar working concentrations, the proposed SAP-LiCl-coated FTHE performs better in terms of vapor sorption compared to its currently available other counterparts. For instance, the maximum sorption amount recorded for PVA-LiCl-coated heat exchanger was accounted as $0.8 \mathrm{~g} / \mathrm{g}$, when the chamber temperature was maintained at $30^{\circ} \mathrm{C}$ with $80 \% \mathrm{RH}$ [10]. At similar working conditions, the net sorption amount recorded for SAP-LiCl-coated FTHE was recorded as high as $1.8 \mathrm{~g} / \mathrm{g}$, suggesting a $125 \%$ increment in the sorption amount. The improvement in DCHE's performance can be explained by shedding light on the molecular structure of the composite desiccant. In particular, compared to other solid desiccants, SAP has a smaller surface area. However, when impregnated with salt such as lithium chloride $(\mathrm{LiCl})$, the surface area of polymer desiccant enhances due to salt crystal formation, which further enhances its vapor sorption capability [16]. Furthermore, upon quantification, the vapor sorption rate was found to attain equilibrium in quick succession of 6000-8000 s. at a relatively lower temperature of $20^{\circ} \mathrm{C}, 25^{\circ} \mathrm{C}$, and $30^{\circ} \mathrm{C}$ for $16.6 \mathrm{wt} \%$ and $33.3 \mathrm{wt} \%$ (ESI Figure S1).

To evaluate the vapor desorption capability of the desiccant during the regeneration process, experiments were conducted at a temperature of $40^{\circ} \mathrm{C}, 50^{\circ} \mathrm{C}, 60^{\circ} \mathrm{C}, 70^{\circ} \mathrm{C}$, and $80^{\circ} \mathrm{C}$ by maintaining the relative humidity at $80 \% \mathrm{RH}$ with processed air inflow of $30^{\circ} \mathrm{C}$. It was observed that the $\mathrm{Al}$ sheet with $16.6 \mathrm{wt} \%$ yields a poor desorption irrespective to change in temperatures. For $33.3 \mathrm{wt} \%$ and $50.0 \mathrm{wt} \%$, vapor desorption kinetics significantly improves corresponding to an increase in the temperature. At relatively lower temperatures such as $40{ }^{\circ} \mathrm{C}$ and $50{ }^{\circ} \mathrm{C}$, desiccants cannot be completely dehydrated for all three desiccant concentrations. However, at a higher desiccant concentration ( $33.3 \mathrm{wt} \%$ and $50.0 \mathrm{wt} \%$ ), vapor desorption significantly improves when regeneration temperature was set at $70{ }^{\circ} \mathrm{C}$ and $80^{\circ} \mathrm{C}$ as the desiccant-coated aluminum sheets can be completely dehydrated to zero. The superior desorption characteristics of the proposed desiccant at higher temperatures might be due to its large vapor capacity during the dehumidification process, which requires higher regeneration temperature towards its complete dehydration. Further, considering that the $16.6 \mathrm{wt} \%$ desiccant-coated Al sheets possess a poor desorption and $33.3 \mathrm{wt} \%$ and $50.0 \mathrm{wt} \%$ desiccant-coated $\mathrm{Al}$ sheets showed a similar 
trend in sorption as well as desorption, $33.3 \mathrm{wt} \%$ was selected as the final coating concentration to apply on the fin-tube heat exchanger for dynamic testing operation.
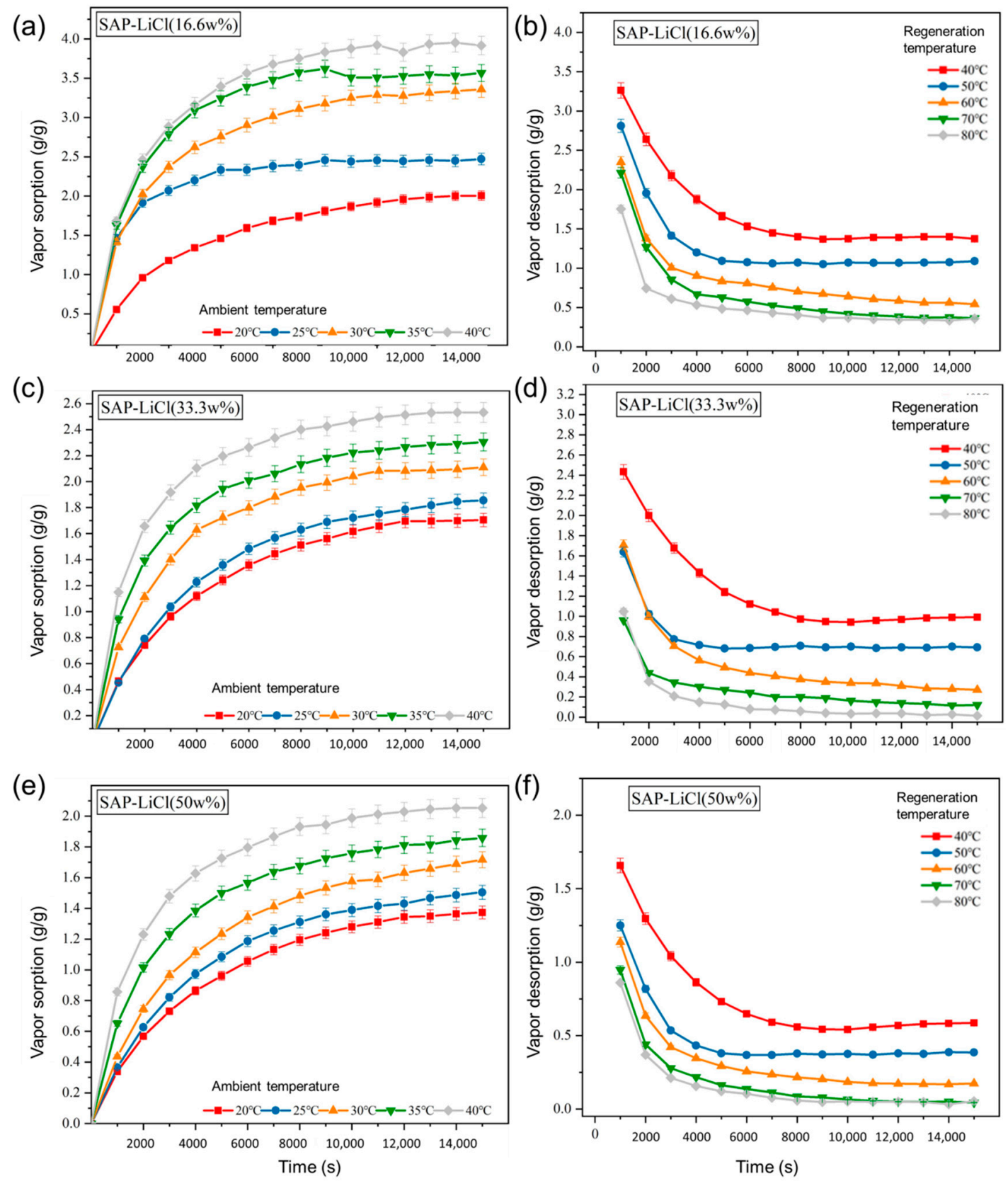

Figure 2. Vapor sorption and desorption kinetics of SAP-LiCl desiccant at the various operating conditions. The first row $(\mathbf{a}, \mathbf{b})$, second row $(\mathbf{c}, \mathbf{d})$, and third row $(\mathbf{e}, \mathbf{f})$ illustrate the vapor sorption and desorption capability of the proposed composite desiccant with $16.6 \mathrm{wt} \%, 33.3 \mathrm{wt} \%$, and $50 \mathrm{wt} \%$, respectively. The results are depicted as Mean $\pm \operatorname{SD}(n=4)$.

\subsection{Performance Analysis of Composite Desiccant-Coated FTHEs in a Dynamic Test Condition}

\subsubsection{Moisture Removal Capability of Desiccant-Coated FTHEs at Different Humidity Conditions}

The underneath Figure 3 illustrates the distribution curve of the air humidity ratio of the desiccant-coated heat exchanger with selected concentration of $33.3 \mathrm{wt} \%$ under different process air humidity conditions, with a processed air inflow maintained at $30{ }^{\circ} \mathrm{C}$. During the experiment, cold and hot water alternatively supplied to the heat exchanger towards dehumidification as well 
as regeneration processes with process times of $30 \mathrm{~min}$ for each cycle. It can be noted that, during the dehumidification process, the cold water is supplied at $25^{\circ} \mathrm{C}$, whereas, during the regeneration process, the supplied water temperature was maintained at $50{ }^{\circ} \mathrm{C}$. As observed, with a relatively lower inlet air humidity condition of $60 \% \mathrm{RH}$, a relatively small change in the humidity ratio was observed during the dehumidification and regeneration process. However, under high humidity conditions of $70 \% \mathrm{RH}$ and $80 \% \mathrm{RH}$, a significant change in the humidity ratio was observed during both the dehumidification as well as the regeneration process. For all the three test conditions, approximately 7-9 min were required to attain the saturated state. It was further observed that the humidity condition of inflow air significantly affects the time required to achieve regeneration. For instance, with $60 \% \mathrm{RH}$, the regeneration was complete after $6 \mathrm{~min}$, whereas it approximately takes $8 \mathrm{~min}$ when the humidity of air was maintained at $80 \% \mathrm{RH}$. However, at this point, it is not very clearly known how the sorption and desorption amount of proposed DCHE changes under various operating conditions such as different regeneration temperatures, process air inflow temperature, switching cyclic time period between humidification and regeneration processes, etc. To elucidate it further, experiments were conducted and illustrated in the following sections.

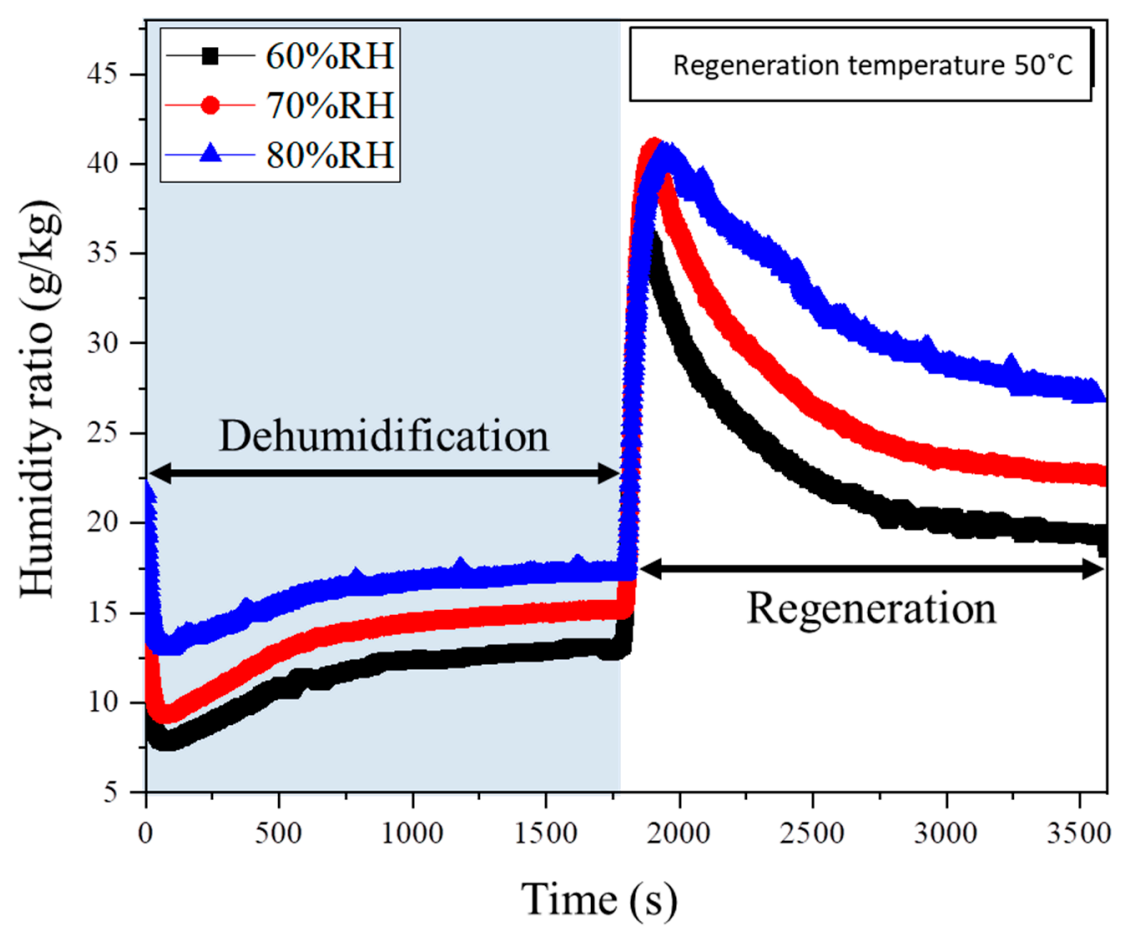

Figure 3. Distribution curves of the outlet air humidity ratio of SAP-LiCl-coated heat exchangers at various humidity conditions of $60 \% \mathrm{RH}, 70 \% \mathrm{RH}$ and $80 \% \mathrm{RH}$. The processed air inflow was maintained at $30^{\circ} \mathrm{C}$ and the water temperature was maintained at $25^{\circ} \mathrm{C}$ and $50{ }^{\circ} \mathrm{C}$ during the dehumidification and regeneration process.

3.2.2. Vapor Sorption or Desorption Capability of Desiccant-Coated FTHEs at Different Operating Conditions

Tables 1 and 2 illustrate the vapor sorption and desorption amount $\left(G_{\text {vap }}\right)$, sorption and desorption amount per unit area $\left(G_{a}\right)$, sorption and desorption amount per unit mass $\left(G_{m}\right)$ of the composite SAP-LiCl-coated FTHE under different regeneration temperatures $\left(50{ }^{\circ} \mathrm{C}, 60{ }^{\circ} \mathrm{C}\right.$, and $\left.70{ }^{\circ} \mathrm{C}\right)$ and humidity conditions $(60 \% \mathrm{RH}, 70 \% \mathrm{RH}, 80 \% \mathrm{RH})$ with two processing air inflow temperature settings of $25^{\circ} \mathrm{C}$ and $30^{\circ} \mathrm{C}$ were tested. To avoid terminological confusion, the air inflow temperature settings of $25^{\circ} \mathrm{C}$ and $30^{\circ} \mathrm{C}$ were coined as Case-I and Case-II, respectively. The vapor sorption and desorption abilities were noticed to be increased, corresponding to the increases in the regeneration temperature and relative humidity for both Case-I and Case-II. It was further observed that at a higher processing air 
inflow temperature of $30^{\circ} \mathrm{C}$ (Case-II), vapor sorption and desorption abilities of the SAP-LiCl-coated heat exchanger improves significantly. For instance, with a regeneration temperature setting at $70{ }^{\circ} \mathrm{C}$ with a humidity air ratio of $80 \% \mathrm{RH}$, the sorption amount $\left(G_{v a p}\right)$ of the DCHE was accounted as $945.06 \mathrm{~g}$ and $1115.1 \mathrm{~g}$, respectively. This suggests a net $17 \%$ improvement in the net sorption ability of the DCHE at a higher processing air inflow temperature of $30^{\circ} \mathrm{C}$ (Case-II). A similar trend in the improvement was further noticed for the DCHE's sorption and desorption amount per unit area $\left(G_{a}\right)$, sorption and desorption amount per unit mass $\left(G_{m}\right)$ for all the other test conditions. This improvement might result from the increase in the humidity ratio of the process air due to the increase in the dry bulb temperature under the same relative humidity ( $\% \mathrm{RH})$ in the processed air. Upon comparison, it was further observed that, under a similar working condition, the sorption and desorption amount of SAP-LiCl-coated FTHE was found to be better compared to silica gel-coated FTHE. For instance, at a processing inlet airflow temperature setting of $30{ }^{\circ} \mathrm{C}$ with humidity ratio of $70 \% \mathrm{RH}$, the sorption amount $\left(G_{\text {vap }}\right)$ of the silica gel-coated FTHE was accounted as low as $86.75 \mathrm{~g}$ upon compared to a sorption amount of $1115.1 \mathrm{~g}$ obtained for an SAP-LiCl-coated FTHE [15]. A similar trend in the improvement was observed for all the remaining test conditions. Hence it can be concluded that the proposed composite desiccant possesses a superlative capability towards moisture removal in any weather condition.

Table 1. Vapor sorption and desorption abilities of SAP-LiCl-coated FTHEs at different operation conditions with processed inlet airflow temperature settings of $25^{\circ} \mathrm{C}$ (Case-I) and $30{ }^{\circ} \mathrm{C}$ (Case-II).

\begin{tabular}{|c|c|c|c|c|c|c|c|}
\hline \multicolumn{8}{|c|}{ Vapor Sorption and Desorption Amount of SAP-LiCl-Coated FTHE } \\
\hline & & \multicolumn{2}{|c|}{$60 \%$ RH } & \multicolumn{2}{|c|}{$70 \%$ RH } & \multicolumn{2}{|c|}{$80 \%$ RH } \\
\hline & $\begin{array}{l}\text { Regeneration } \\
\text { Temperature }\end{array}$ & $\begin{array}{l}\text { Sorption } \\
\text { Amount }\end{array}$ & $\begin{array}{c}\text { Desorption } \\
\text { Amount }\end{array}$ & $\begin{array}{l}\text { Sorption } \\
\text { Amount }\end{array}$ & $\begin{array}{c}\text { Desorption } \\
\text { Amount }\end{array}$ & $\begin{array}{l}\text { Sorption } \\
\text { Amount }\end{array}$ & $\begin{array}{c}\text { Desorption } \\
\text { Amount }\end{array}$ \\
\hline \multicolumn{8}{|c|}{ Case-I-Processed air inflow temperature of $25^{\circ} \mathrm{C}$} \\
\hline \multirow{3}{*}{$G_{\text {vap }}(\mathrm{g})$} & $50{ }^{\circ} \mathrm{C}$ & 252.3 & 361.8 & 289.6 & 424.9 & 348.9 & 457.8 \\
\hline & $60{ }^{\circ} \mathrm{C}$ & 287.7 & 526.6 & 346.7 & 597.4 & 402.2 & 709.1 \\
\hline & $70^{\circ} \mathrm{C}$ & 315.0 & 667.6 & 380.3 & 777.6 & 442.5 & 945.1 \\
\hline \multirow{3}{*}{$\begin{array}{c}G_{a} \\
\left(\mathrm{~g} / \mathrm{cm}^{2}\right)\end{array}$} & $50{ }^{\circ} \mathrm{C}$ & 0.052 & 0.075 & 0.060 & 0.088 & 0.072 & 0.095 \\
\hline & $60^{\circ} \mathrm{C}$ & 0.060 & 0.109 & 0.072 & 0.124 & 0.083 & 0.147 \\
\hline & $70{ }^{\circ} \mathrm{C}$ & 0.065 & 0.138 & 0.079 & 0.161 & 0.092 & 0.196 \\
\hline \multirow{3}{*}{$\begin{array}{l}G_{m} \\
(\mathrm{~g} / \mathrm{g})\end{array}$} & $50{ }^{\circ} \mathrm{C}$ & 0.661 & 0.948 & 0.759 & 1.114 & 0.914 & 1.200 \\
\hline & $60^{\circ} \mathrm{C}$ & 0.754 & 1.380 & 0.909 & 1.566 & 1.054 & 1.859 \\
\hline & $70{ }^{\circ} \mathrm{C}$ & 0.826 & 1.750 & 0.997 & 2.038 & 1.160 & 2.478 \\
\hline \multicolumn{8}{|c|}{ Case-II-Processed air inflow temperature of $30^{\circ} \mathrm{C}$} \\
\hline \multirow{3}{*}{$G_{\text {vap }}(\mathrm{g})$} & $50{ }^{\circ} \mathrm{C}$ & 282.9 & 420.5 & 309.0 & 504.0 & 342.0 & 584.4 \\
\hline & $60^{\circ} \mathrm{C}$ & 303.7 & 641.3 & 396.0 & 732.9 & 418.0 & 1006.1 \\
\hline & $70{ }^{\circ} \mathrm{C}$ & 336.8 & 800.9 & 432.9 & 969.7 & 486.4 & 1115.1 \\
\hline \multirow{3}{*}{$\begin{array}{c}G_{a} \\
\left(\mathrm{~g} / \mathrm{cm}^{2}\right)\end{array}$} & $50{ }^{\circ} \mathrm{C}$ & 0.059 & 0.087 & 0.064 & 0.104 & 0.071 & 0.121 \\
\hline & $60{ }^{\circ} \mathrm{C}$ & 0.063 & 0.133 & 0.082 & 0.152 & 0.087 & 0.208 \\
\hline & $70{ }^{\circ} \mathrm{C}$ & 0.070 & 0.166 & 0.090 & 0.201 & 0.101 & 0.231 \\
\hline \multirow{3}{*}{$\begin{array}{c}G_{m} \\
(g / g)\end{array}$} & $50{ }^{\circ} \mathrm{C}$ & 0.742 & 1.102 & 0.810 & 1.321 & 0.879 & 1.502 \\
\hline & $60^{\circ} \mathrm{C}$ & 0.796 & 1.681 & 1.038 & 1.921 & 1.075 & 2.586 \\
\hline & $70{ }^{\circ} \mathrm{C}$ & 0.883 & 2.099 & 1.135 & 2.542 & 1.250 & 2.867 \\
\hline
\end{tabular}


Table 2. Vapor sorption and desorption amount $\left(G_{v a p}\right)$ of SAP-LiCl coated for the first and overall cycles with different inlet airflow conditions (Case-I, Case-II, and Case-III).

\begin{tabular}{|c|c|c|c|c|c|c|c|c|c|c|c|c|}
\hline \multicolumn{13}{|c|}{ Dehumidification and Regeneration Amount $\left(G_{v a p}\right)$ for an Individual First Cycle and Overall Cycle Time. } \\
\hline & \multicolumn{4}{|c|}{ Case-I: $25^{\circ} \mathrm{C} / 70 \% \mathrm{RH}$} & \multicolumn{4}{|c|}{ Case-II: ${ }^{\circ} \mathrm{C} / 70 \% \mathrm{RH}$} & \multicolumn{4}{|c|}{ Case-III: $35{ }^{\circ} \mathrm{C} / 70 \% \mathrm{RH}$} \\
\hline & \multicolumn{2}{|c|}{$\begin{array}{c}\text { Sorption } \\
\text { Amount (g) }\end{array}$} & \multicolumn{2}{|c|}{$\begin{array}{l}\text { Desorption } \\
\text { Amount (g) }\end{array}$} & \multicolumn{2}{|c|}{$\begin{array}{c}\text { Sorption } \\
\text { Amount (g) }\end{array}$} & \multicolumn{2}{|c|}{$\begin{array}{l}\text { Desorption } \\
\text { Amount (g) }\end{array}$} & \multicolumn{2}{|c|}{$\begin{array}{c}\text { Sorption } \\
\text { Amount (g) }\end{array}$} & \multicolumn{2}{|c|}{$\begin{array}{l}\text { Desorption } \\
\text { Amount (g) }\end{array}$} \\
\hline $\begin{array}{l}\text { Cycle } \\
\text { Time } \\
\text { (min) }\end{array}$ & $\begin{array}{l}\text { First } \\
\text { Cycle }\end{array}$ & Overall & $\begin{array}{l}\text { First } \\
\text { Cycle }\end{array}$ & Overall & $\begin{array}{l}\text { First } \\
\text { Cycle }\end{array}$ & Overall & $\begin{array}{l}\text { First } \\
\text { Cycle }\end{array}$ & Overall & $\begin{array}{l}\text { First } \\
\text { Cycle }\end{array}$ & Overall & $\begin{array}{l}\text { First } \\
\text { Cycle }\end{array}$ & Overall \\
\hline 10 & 67 & 801 & 86 & 1026 & 85 & 1018 & 101 & 1203 & 100 & 128 & 1204 & 1536 \\
\hline 20 & 127 & 764 & 186 & 1113 & 161 & 964 & 243 & 1456 & 198 & 280 & 1192 & 1680 \\
\hline 40 & 222 & 666 & 311 & 933 & 287 & 861 & 401 & 1203 & 361 & 495 & 1084 & 1486 \\
\hline 60 & 308 & 616 & 398 & 796 & 386 & 772 & 538 & 1076 & 504 & 683 & 1009 & 1366 \\
\hline
\end{tabular}

\subsubsection{Thermal Coefficient of Performance ( $\left.\mathrm{COP}_{\text {th }}\right)$}

The overall thermal coefficients of performance $\left(\mathrm{COP}_{\text {th }}\right)$ of the proposed DCHE under different operating conditions were quantified and illustrated in Figure 4 below for both the test cases (processed inlet airflow temperature setting of $25{ }^{\circ} \mathrm{C}$ (Case-I) and $30{ }^{\circ} \mathrm{C}$ (Case-II)). It was observed that the value $\mathrm{COP}_{\text {th }}$ is directly proportional to the relative humidity in the process air for both the test cases. The overall $\mathrm{COP}_{\text {th }}$ significantly improved when the air inflow temperature was set at $30^{\circ} \mathrm{C}$ (Case-II) rather than $25^{\circ} \mathrm{C}$ (Case-I). For instance, with a regeneration temperature setting at $70{ }^{\circ} \mathrm{C}$ with $80 \% \mathrm{RH}$, the $\mathrm{COP}_{\text {th }}$ of DCHE was found to be a maximum of 0.39 and 0.34 , respectively, for both Case-II and Case-I, suggesting a $17 \%$ net improvement. As mentioned in the earlier section, corresponding to the increase in the dry bulb temperature under the same relative humidity of the process air increases the vapor pressure in process air that boosts sorption abilities resulting in a net enhancement of the system's overall $\mathrm{COP}_{\text {th }}$. It can be further noted that, with a similar environmental setting, with a processed airflow temperature setting of $30^{\circ} \mathrm{C}$, the $\mathrm{COP}_{\text {th }}$ of MOF-coated heat exchanger has a value of 0.1662 [ESI Table S1, unpublished work]. Moreover, the overall COP th $_{\text {of }}$ the DCHE was found to be inversely proportional to the increase in regeneration temperature. For instance, in test Case-II, with humidity ratio of $80 \% \mathrm{RH}$, the $\mathrm{COP}_{\text {th }}$ was quantified as $0.39,0.33$, and 0.31 when the regeneration temperature was set at $50{ }^{\circ} \mathrm{C}, 60^{\circ} \mathrm{C}$, and $70{ }^{\circ} \mathrm{C}$, respectively. The results above further explain that the proposed composite polymer (SAP- $\mathrm{LiCl}$ )-coated heat exchanger depicts a net $60 \%$ improvement in the overall $\mathrm{COP}_{\text {th }}$ compared to the MOF-coated heat exchanger. 


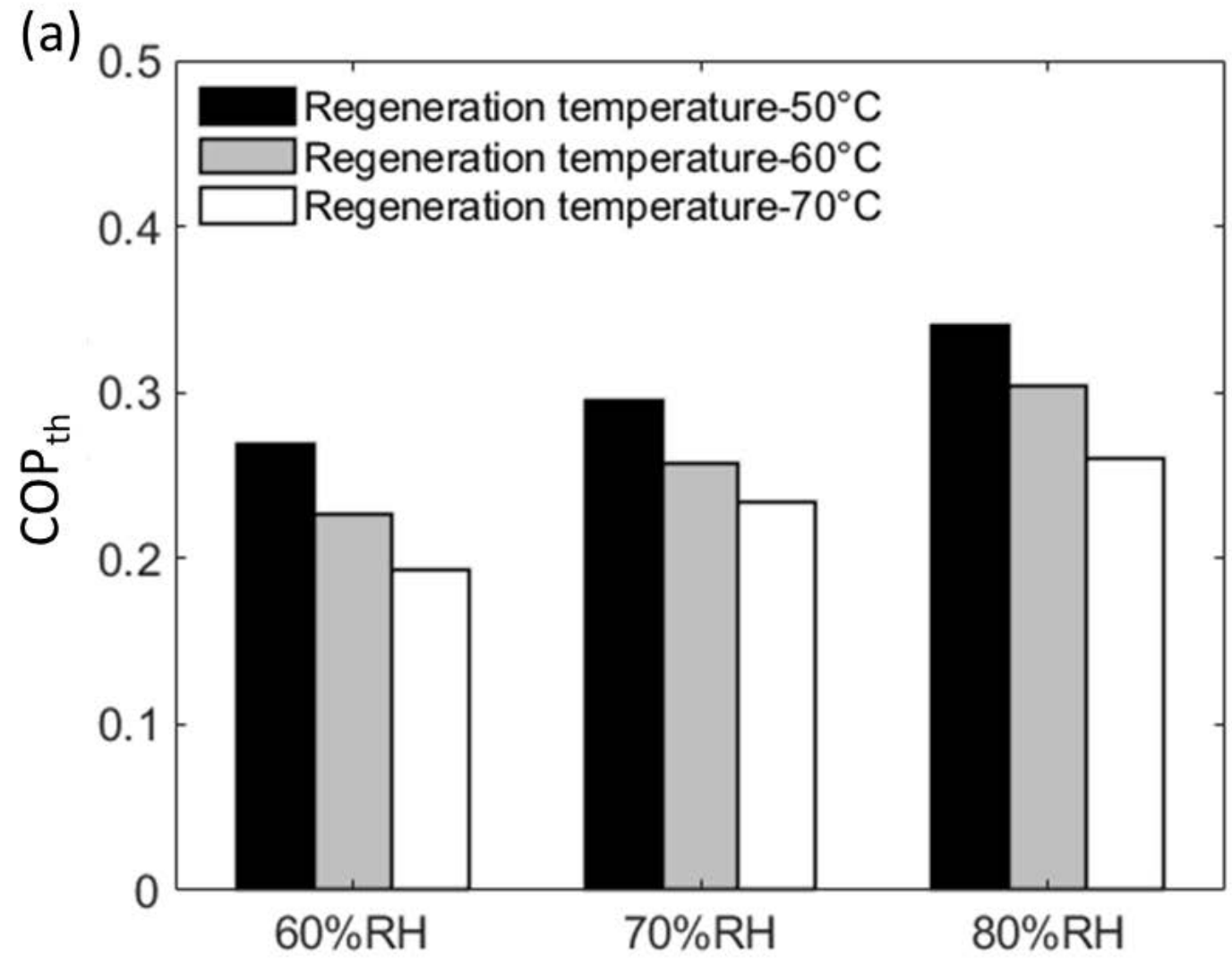

(b)

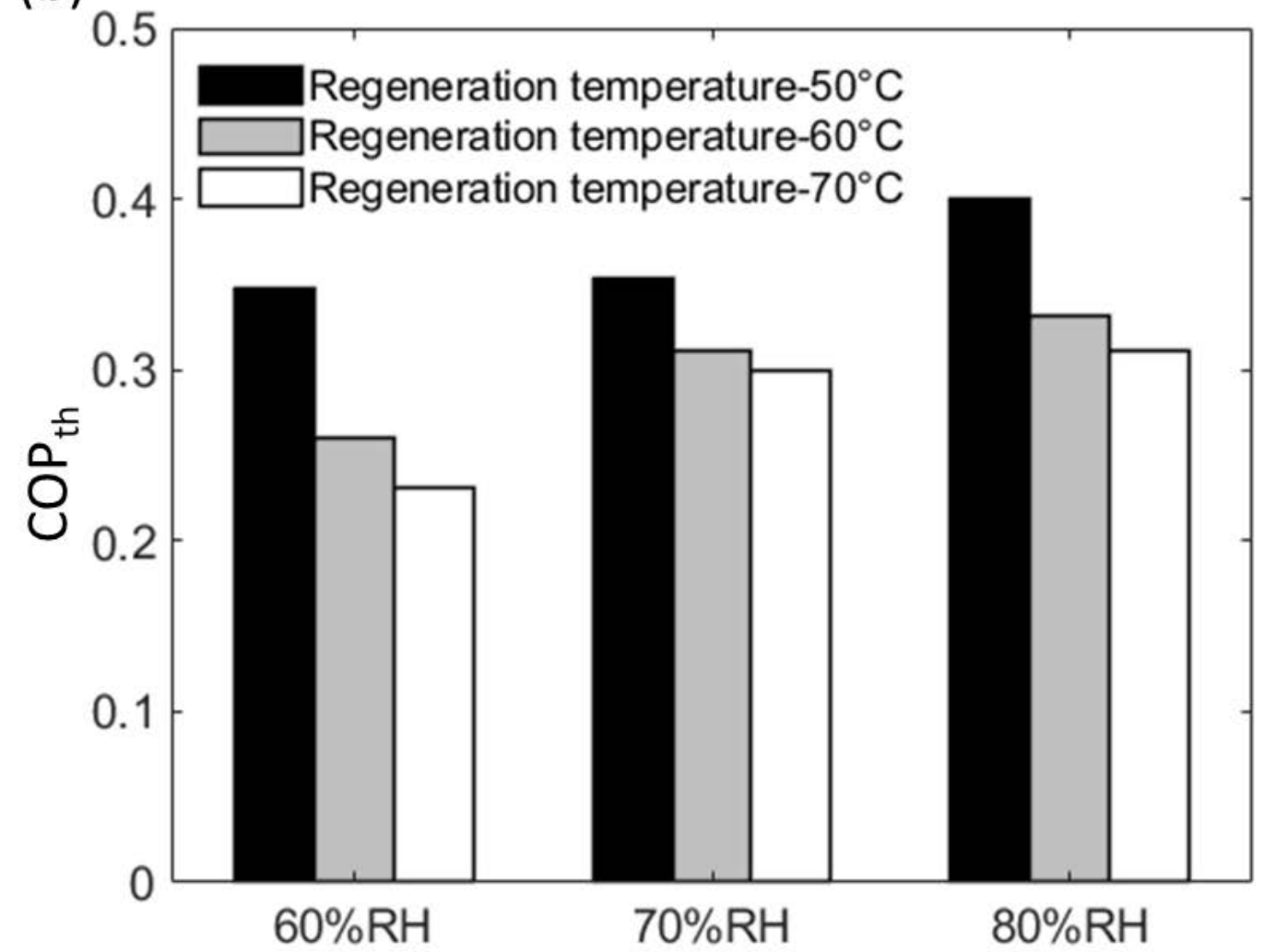

Figure 4. Overall thermal performance coefficient $\left(\mathrm{COP}_{\text {th }}\right)$ of $\mathrm{SAP}-\mathrm{LiCl}$ composite polymer desiccant under different regeneration temperature and humidity conditions at processed air inflow temperature setting of (a) $25^{\circ} \mathrm{C}$ (Case-I) and (b) $30^{\circ} \mathrm{C}$ (Case-II), respectively. The uncertainty of $\mathrm{COP}_{\text {th }}$ was found within a range of $\pm 3.7 \%$. 


\subsubsection{Moisture Removal Capability of Desiccant-Coated FTHE with Different Cyclic Switching Time}

It has been earlier observed that, with suitable switching time in the dehumidification and regeneration process, the performance of the DCHE can be improved significantly [10,15]. To evaluate the performance of SAP-LiCl-coated FTHEs under humidity conditions of $70 \% \mathrm{RH}$ and regeneration temperature of $50^{\circ} \mathrm{C}$, an experiment was conducted by tuning to various switching times of $10 \mathrm{~min}$, $20 \mathrm{~min}, 40 \mathrm{~min}$, and $60 \mathrm{~min}$ for an overall time period of $120 \mathrm{~min}$. The tests were conducted for three processes air inflow temperature settings of $25^{\circ} \mathrm{C}$ (Case-I), $30^{\circ} \mathrm{C}$ (Case-II) and $35^{\circ} \mathrm{C}$ (Case-III). The humidity ratio curves for the three test cases are illustrated in Figure 5 below. It was observed for all the tested cyclic switching times that the magnitude of humidity ratio was higher for Case-III compared to Case-II and Case-I. This describes even with the tuning of switching time that the DCHE performs better in terms of vapor sorption and desorption, with a higher processed air inflow temperature setting. It was further observed that, corresponding to the increase in cyclic switching time, the sorption and desorption amounts during the dehumidification and regeneration process increases significantly during the first individual cycle (Table 2). This resulted from the longer sorption and desorption time periods in the case with a longer switching time cycle. However, the net sorption as well as desorption amount for an overall cycle decreases compared to a shorter cyclic switching time after an overall time period of $120 \mathrm{~min}$. For instance, in test Case-II, the vapor desorption amount for an individual and overall cycle was accounted as $101 \mathrm{~g}$ and $1203 \mathrm{~g}$ with a cyclic switching time of $10 \mathrm{~min}$, which further changes to $538 \mathrm{~g}$ and $1076 \mathrm{~g}$, respectively, when the cyclic switching time was tuned to $60 \mathrm{~min}$, suggesting an overall decrease in the sorption and desorption amounts with a larger cyclic switching time. For the test case with a shorter switching cycle time, even the sorption and desorption amount in the first individual cycle is less, yet it significantly increases corresponding to the overall time period due to the increase in number of cycles. Similarly, for a longer switching cyclic time, although the vapor sorption and desorption capabilities $(\mathrm{g} / \mathrm{g})$ are greater in the first switching cycle, as the system underwent less individual cycle, the net vapor sorption and desorption amounts decrease. For instance, for Case-I, the net vapor sorption amount for the first cycle was quantified as $67 \mathrm{~g}$ for a $10 \mathrm{~min}$ switching time cycle, which further improves to $308 \mathrm{~g}$ when the cyclic switching time was tuned to $60 \mathrm{~min}$, suggesting a net improvement in vapor sorption amount corresponding to the first cycle corresponding to an increase in switching cycle time. However, the system underwent 12 and 2 individual cycles for an overall time period of $120 \mathrm{~min}$, when switching cycle time is tuned as $10 \mathrm{~min}$ and $60 \mathrm{~min}$, respectively. Corresponding to 12 and 2 individual cycles, the overall sorption amount was recorded as $801 \mathrm{~g}$ and $616 \mathrm{~g}$ after the overall cycle of $120 \mathrm{~min}$. Similar trends in results are illustrated for sorption and desorption amount for the test cases I, II, and III, suggesting that a larger cyclic switching time may reduce the vapor sorption and desorption amount for an overall cycle. However, from the above results, it was not conclusive how the overall performance of the DCHE was affected in terms of expenditure. To correlate the energy budget to the DCHE's performance corresponding to the tung of cyclic switching time, the thermal coefficient performance $\left(\mathrm{COP}_{\text {th }}\right)$ of the DCHE corresponding to different cyclic switching time was quantified as described in the next section. 

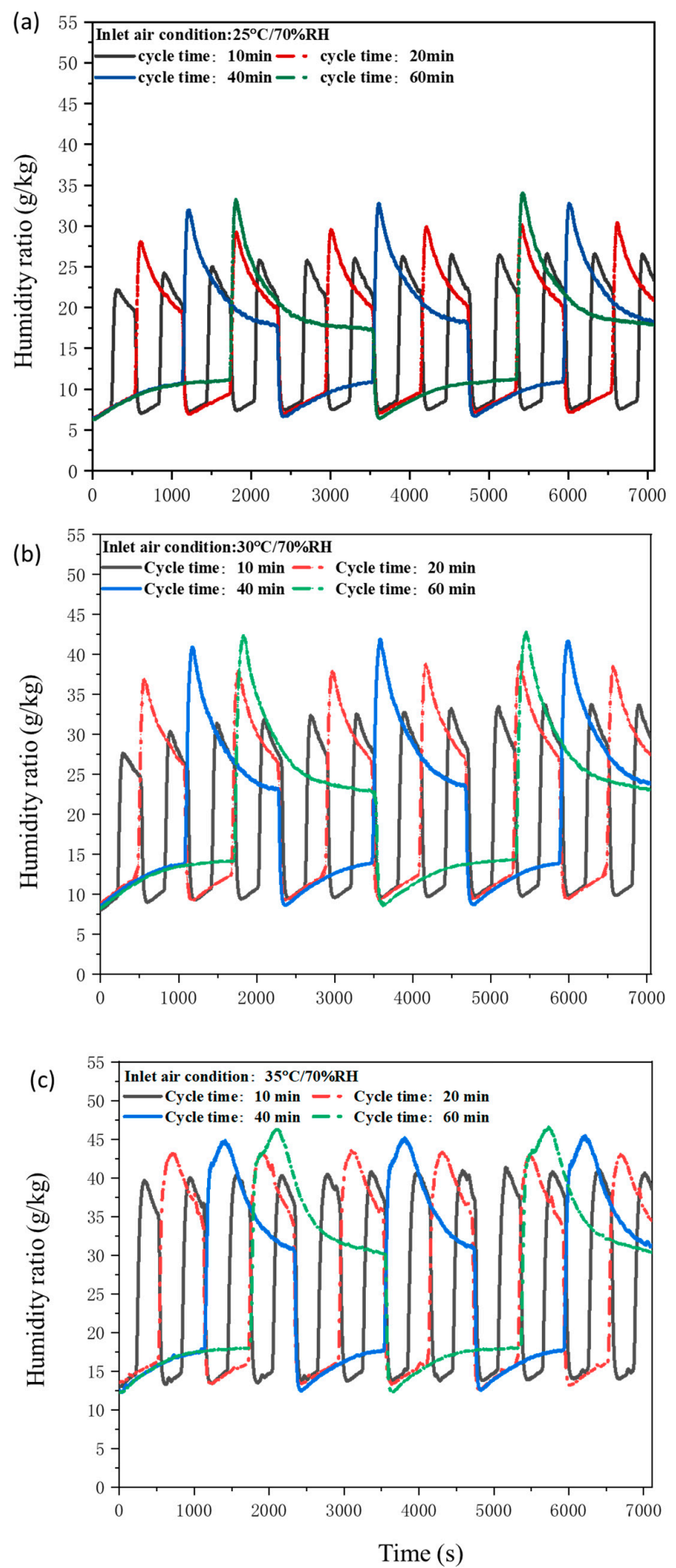

Figure 5. Distribution curves of the outlet air humidity ratio corresponding to cyclic switching times of $10 \mathrm{~min}, 20 \mathrm{~min}, 40 \mathrm{~min}$, and $60 \mathrm{~min}$ for DCHE under similar regeneration temperature of $50{ }^{\circ} \mathrm{C}$ and humidity conditions ( $70 \% \mathrm{RH})$ at processed air inflow temperature settings of (a) $25^{\circ} \mathrm{C}$ (Case-I), (b) $30{ }^{\circ} \mathrm{C}$ (Case-II), and (c) $35^{\circ} \mathrm{C}$ (Case-III), respectively. 
3.2.5. The Overall and Instantaneous $\mathrm{COP}_{\text {th }}$ of Desiccant-Coated FTHE Corresponding to Different Cyclic Switching Times

The overall coefficient of performance (COP th $)$ of SAP-LiCl-coated FTHE under different cyclic switching times of $10 \mathrm{~min}, 20 \mathrm{~min}, 40 \mathrm{~min}$, and $60 \mathrm{~min}$ for the first individual cycle and for an overall time period of $120 \mathrm{~min}$ were quantified and illustrated in Table 3 below. It was observed that, irrespective of the cyclic switching time, the individual (first cycle) as well as overall $\mathrm{COP}_{\text {th }}$ was highest for test Case-III. For instance, at inlet airflow temperature of $25^{\circ} \mathrm{C}$ (Case-I), the overall $\mathrm{COP}_{\text {th }}$ for the four different cyclic switching times were accounted as $0.1940,0.2673,0.3084$, and 0.3254 , respectively which, further improved to $0.3693,0.4939,0.5913$, and 0.6207 , respectively, when the inlet airflow was tuned to $35^{\circ} \mathrm{C}$ (Case-III). This suggests a net improvement in the thermal coefficient, with an increment in the processed airflow temperature. It was further observed that, irrespective of inflow condition, the $\mathrm{COP}_{\text {th }}$ value increases, corresponding to an increase in the cyclic switching time. For Case-III, during the first cycle, $\mathrm{COP}_{\text {th }}$ was accounted as $0.3612,0.4887,0.5895$, and 0.6318 , respectively, when cyclic switching time was set as $10 \mathrm{~min}, 20 \mathrm{~min}, 40 \mathrm{~min}$, and $60 \mathrm{~min}$, respectively, suggesting an increment in the $\mathrm{COP}_{\text {th }}$ with larger cyclic switching times. For instance, with processed air inflow temperature, relative humidity and regeneration temperature setting of $30{ }^{\circ} \mathrm{C}, 70 \% \mathrm{RH}$ and $70{ }^{\circ} \mathrm{C}$, there was a net $58 \%$ improvement in the $\mathrm{COP}_{\text {th }}$ when the cyclic switching time was tuned to $60 \mathrm{~min}$ instead of $10 \mathrm{~min}$. Similarly, with analogues inlet process airflow condition, when the inlet air temperature was set at $35{ }^{\circ} \mathrm{C}$, there was a net $68 \%$ improvement. A similar trend of increment in $\mathrm{COP}_{\text {th }}$ was noticed for all the test cases for an overall cyclic time period of $120 \mathrm{~min}$, suggesting an improvement in energy efficiency corresponding to larger cyclic switching times. However, as delineated in the previous Section 3.2.4 (Table 2), a longer cyclic switching time reduces the vapor sorption as well as desorption amounts for an overall time period of $120 \mathrm{~min}$. However, it was observed hereby that there is an overall improvement to the $\mathrm{COP}_{\text {th }}$ corresponding to longer cyclic switching times. To shed light on this aspect and to delineate the underlying phenomena, the energy expenditure in terms of cooling capacity during the sorption process as well as the energy consumption in sorption and desorption processes for Case-III (maximum improvement in the $\mathrm{COP}_{\text {th }}$ ) were quantified for the first individual cycle and illustrated in Figure 6 below. As observed, corresponding to an increase in the cyclic switching time, the cooling capacity in the sorption process and the energy consumption in both processes gradually increase as well. However, with the increase in the switching cyclic time, the increment of energy consumption in both processes is less than that of the cooling capacity in the sorption process. This indicates that, in the case of a short switching cyclic time, the energy loss in terms of the cooling capacity gain is greater due to frequent operational mode switching, which results in the $\mathrm{COP}_{\text {th }}$ value in the individual cycle gradually increasing with the increase in the switching cyclic time. The improvement in each individual cycle further improves the overall $\mathrm{COP}_{\text {th }}$ in an overall cycle.

Table 3. $\mathrm{COP}_{\text {th }}$ of SAP-LiCl-coated FTHE under different cyclic switching times for both test cases.

\begin{tabular}{ccccccc}
\hline \multicolumn{7}{c}{ COP $_{\text {th }}$ of DCHE under Different Switching Times } \\
\hline $\begin{array}{c}\text { Cycle } \\
\text { Time } \\
(\mathbf{m i n})\end{array}$ & First Cycle & Overall & First Cycle & Overall & First Cycle & Overall \\
\hline 10 & & & & & & \\
\hline 20 & 0.1890 & 0.1940 & 0.2799 & 0.2885 & 0.3612 & 0.3693 \\
40 & 0.2649 & 0.2673 & 0.3838 & 0.3837 & 0.4887 & 0.4939 \\
60 & 0.3213 & 0.3084 & 0.4539 & 0.4659 & 0.5895 & 0.5913 \\
\hline
\end{tabular}




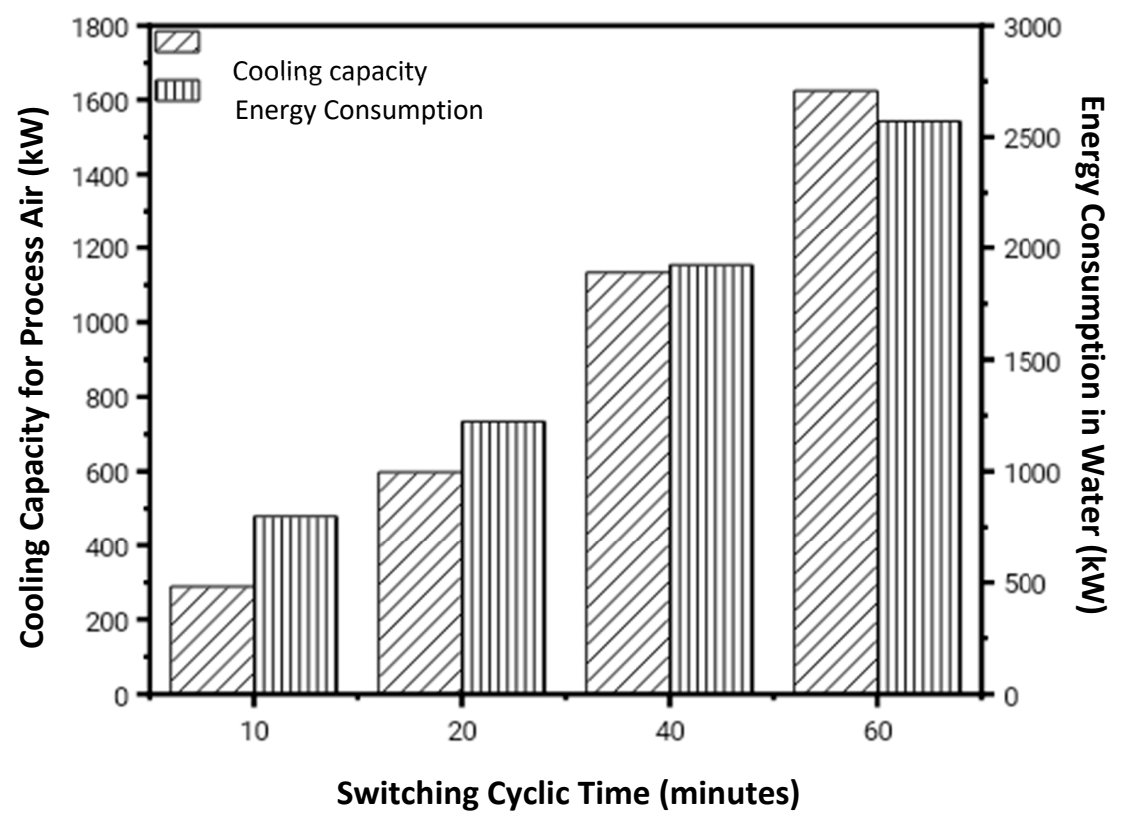

Figure 6. Energy expenditure in terms of heat generation during the adsorption and desorption process with processed airflow temperature of $35{ }^{\circ} \mathrm{C}$ with $70 \% \mathrm{RH}$ for various switching cyclic minutes of $10 \mathrm{~min}, 20 \mathrm{~min}, 40 \mathrm{~min}$, and $60 \mathrm{~min}$. The uncertainty in energy expenditure quantification is found in a range of $\pm 4.75 \%$.

\section{Conclusions}

In this study, a composite polymer desiccant material, SAP-LiCl, was tested for its moisture removal efficacy through static and dynamic testing conditions. The results illustrate that the proposed desiccant possesses a superlative dehumidification capacity compared to the other currently available desiccant materials. Based on the experimental results, the following conclusions can be derived as listed underneath.

(1) The static experiment was carried out with a desiccant-coated Al sheet in a programmable constant temperature and humidity system. For superior sorption as well as desorption functionality, the final weight concentration (wt \%) of SAP in the polymer composite desiccant solution (SAP-LiCl) was optimized as $33 \mathrm{wt} \%$.

(2) Under high humidity conditions (70\% RH and $80 \% \mathrm{RH})$, a significant change in the humidity ratio curve was noticed during both the dehumidification as well as the regeneration process, suggesting the efficacy of the proposed desiccant-coated FTHE in high humidity conditions.

(3) The sorption and desorption amount of SAP-LiCl-coated FTHE was found to be superior compared to silica gel-coated FTHE. For instance, at a processing inlet airflow temperature setting of $30{ }^{\circ} \mathrm{C}$ with humidity ratio of $70 \% \mathrm{RH}$, the sorption amount $\left(G_{v a p}\right)$ of the SAP-LiCl-coated FTHE was accounted as $1115.1 \mathrm{~g}$ compared to a value of $86.75 \mathrm{~g}$ of silica gel-coated FTHE.

(4) The sorption amount and $\mathrm{COP}_{\text {th }}$ of DCHE were found to be better with processed air inflow with a temperature setting of $30^{\circ} \mathrm{C}$ compared to $25^{\circ} \mathrm{C}$. With processed air inflow temperature, relative humidity and regeneration temperature setting of $30^{\circ} \mathrm{C}, 80 \% \mathrm{RH}$ and $70{ }^{\circ} \mathrm{C}, \mathrm{DCHE}^{\prime} \mathrm{s} \mathrm{COP}_{\text {th }}$ is recorded as high as 0.39 .

(5) The dehumidification ability of SAP-LiCl-coated FTHE was analyzed under different switching time cycles, and it was observed that with the increase in the switching time cycle, the overall thermal coefficient of performance increases corresponding to the decrease in the overall sorption and desorption ability of the DCHEs. Energy analysis suggests that a longer switching cycle decreases energy loss during each cycle, resulting in a net improvement in the thermal coefficient of performance $\left(\mathrm{COP}_{\text {th }}\right)$ of DCHE. 
These proposed desiccant's applications can also be extended to absorption chillers, heat pumps, and water regenerators and is the future direction of our ongoing research.

Supplementary Materials: The following are available online at http://www.mdpi.com/2071-1050/12/22/9673/s1, ESI Text: Figure S1 and Table S1.

Author Contributions: W.J.L. and B.P. conceived and designed the experiments; W.J.L., H.W.W., and Y.S.C. performed the experiments; W.J.L., B.P., and H.W.W. analyzed the data; W.J.L. and B.P. contributed reagents/materials/analysis tools; B.P., H.W.W., and W.J.L. wrote the paper. All authors have read and agreed to the published version of the manuscript.

Funding: This research received no external funding.

Acknowledgments: The author gratefully acknowledges the financial support provided to this study by the Industrial Technology Research Institute under Grant MOST 108-2221-E-167-011-MY2.

Conflicts of Interest: The authors declare no conflict of interest.

\section{Nomenclatures}

$\begin{array}{ll}M_{\text {vap }} & \text { Moisture removal rate } \\ \dot{m}_{a} & \text { Mass flow rate of air } \\ W_{a, \text { in }} & \text { Humidity ratio of process air inlet } \\ W_{a, \text { out }} & \text { Humidity ratio of process air outlet } \\ \mathrm{G}_{\mathrm{vap}} & \text { Vapor sorption/desorption amount } \\ \mathrm{T} & \text { Period for vapor sorption or desorption } \\ \mathrm{G}_{a} & \text { Vapor sorption/desorption amounts per unit area of desiccant } \\ A_{\text {fin }} & \text { Total area of the fins } \\ \mathrm{G}_{\mathrm{m}} & \text { Sorption or desorption ability per unit mass of the desiccant } \\ \mathrm{COP}_{\mathrm{th}} & \text { Coefficient of thermal performance } \\ \mathrm{C}_{\mathrm{p}} & \text { Specific heat } \\ \mathrm{Q}_{\mathrm{reg}} & \text { Average heat exchange of water in an effective regeneration process } \\ \mathrm{Q}_{\text {cool }} & \text { The ratio of the total energy exchange of the processed air in an effective } \\ \mathrm{RH}_{\mathrm{o}} & \text { dehumidification process } \\ T_{h, \text { in }} & \text { Relative humidity in percentage } \\ h_{a, \text { out }} & \text { Temperatures of water supply to DCHE } \\ h_{a, \text { in }} & \text { Enthalpies of the process air after of DCHE } \\ \dot{m}_{\text {water }} & \text { Enthalpies of the process before of DCHE } \\ T_{h, \text { out }} & \text { Mass flow rate of water }\end{array}$

\section{References}

1. Vivekh, P.; Kumja, M.; Bui, D.; Chua, K. Recent developments in solid desiccant coated heat exchangers-A review. Appl. Energy 2018, 229, 778-803. [CrossRef]

2. Ma, Z.; Song, J.; Zhang, J. Energy consumption prediction of air-conditioning systems in buildings by selecting similar days based on combined weights. Energy Build. 2017, 151, 157-166. [CrossRef]

3. Tu, Y.; Wang, R.; Ge, T.; Zheng, X. Comfortable, high-efficiency heat pump with desiccant-coated, water-sorbing heat exchangers. Sci. Rep. 2017, 7, 40437. [CrossRef] [PubMed]

4. Saeed, A.; Al-Alili, A. A review on desiccant coated heat exchangers. Sci. Technol. Built Environ. 2017, 23, 136-150. [CrossRef]

5. Zheng, X.; Wang, R.; Ma, W. Dehumidification assessment for desiccant coated heat exchanger systems in different buildings and climates: Fast choice of desiccants. Energy Build. 2020, 110083. [CrossRef]

6. Wu, X.; Ge, T.; Dai, Y.; Wang, R. Review on substrate of solid desiccant dehumidification system. Renew. Sustain. Energy Rev. 2018, 82, 3236-3249. [CrossRef]

7. Hu, L.; Ge, T.; Jiang, Y.; Wang, R. Performance study on composite desiccant material coated fin-tube heat exchangers. Int. J. Heat Mass Transf. 2015, 90, 109-120. [CrossRef] 
8. Kummer, H.; Jeremias, F.; Warlo, A.; Füldner, G.; Fröhlich, D.; Janiak, C.; Gläser, R.; Henninger, S.K. A functional full-scale heat exchanger coated with aluminum fumarate metal-organic framework for adsorption heat transformation. Ind. Eng. Chem. Res. 2017, 56, 8393-8398. [CrossRef]

9. Kim, H.; Yang, S.; Rao, S.R.; Narayanan, S.; Kapustin, E.A.; Furukawa, H.; Umans, A.S.; Yaghi, O.M.; Wang, E.N. Water harvesting from air with metal-organic frameworks powered by natural sunlight. Science 2017, 356, 430-434. [CrossRef] [PubMed]

10. Vivekh, P.; Islam, M.; Chua, K. Experimental performance evaluation of a composite superabsorbent polymer coated heat exchanger based air dehumidification system. Appl. Energy 2020, 260, 114256. [CrossRef]

11. Leiming, H.; Tianshu, G.; Yu, J.; Ruzhu, W. Hygroscopic property of metal matrix composite desiccant. J. Refrig. 2014, 2, 12 .

12. Ge, T.; Zhang, J.; Dai, Y.; Wang, R. Experimental study on performance of silica gel and potassium formate composite desiccant coated heat exchanger. Energy 2017, 141, 149-158. [CrossRef]

13. Cui, S.; Qin, M.; Marandi, A.; Steggles, V.; Wang, S.; Feng, X.; Nouar, F.; Serre, C. Metal-Organic Frameworks as advanced moisture sorbents for energy-efficient high temperature cooling. Sci. Rep. 2018, 8, 1-9. [CrossRef] [PubMed]

14. Zheng, X.; Wang, R.; Ge, T. Experimental study and performance predication of carbon based composite desiccants for desiccant coated heat exchangers. Int. J. Refrig. 2016, 72, 124-131. [CrossRef]

15. Chang, C.-C.; Luo, W.-J.; Lu, C.-W.; Cheng, Y.-S.; Tsai, B.-Y.; Lin, Z.-H. Effects of process air conditions and switching cycle period on dehumidification performance of desiccant-coated heat exchangers. Sci. Technol. Built Environ. 2017, 23, 81-90. [CrossRef]

16. Yang, Y.; Rana, D.; Lan, C.Q. Development of solid super desiccants based on a polymeric superabsorbent hydrogel composite. RSC Adv. 2015, 5, 59583-59590. [CrossRef]

17. Luo, W.-J.; Faridah, D.; Fasya, F.R.; Chen, Y.-S.; Mulki, F.H.; Adilah, U.N. Performance Enhancement of Hybrid Solid Desiccant Cooling Systems by Integrating Solar Water Collectors in Taiwan. Energies 2019, 12, 3470. [CrossRef]

18. Lee, J.; Lee, D.-Y. Sorption characteristics of a novel polymeric desiccant. Int. J. Refrig. 2012, 35, $1940-1949$. [CrossRef]

19. Kline, S.J. Describing uncertainty in single sample experiments. Mech. Eng. 1953, 75, 3-8.

20. Li, K.-Y.; Luo, W.-J.; Tsai, B.-Y.; Kuan, Y.-D. Performance Analysis of Two-Stage Solid Desiccant Densely Coated Heat Exchangers. Sustainability 2020, 12, 7357. [CrossRef]

Publisher's Note: MDPI stays neutral with regard to jurisdictional claims in published maps and institutional affiliations.

(C) 2020 by the authors. Licensee MDPI, Basel, Switzerland. This article is an open access article distributed under the terms and conditions of the Creative Commons Attribution (CC BY) license (http://creativecommons.org/licenses/by/4.0/). 